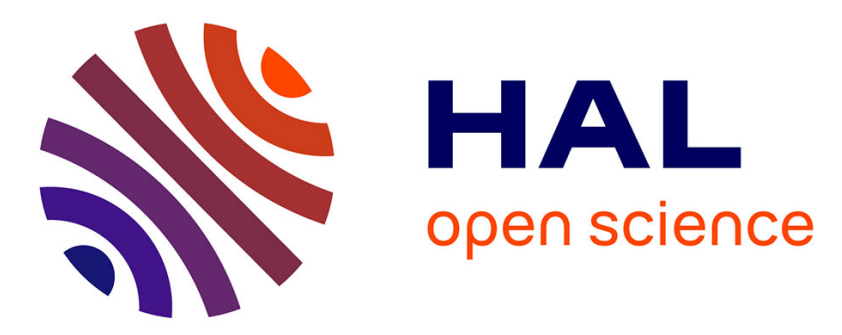

\title{
What is the best distribution for pollution abatement efforts? Information for optimizing the WFD Programs of measures
}

F. Destandau, A. Nafi

\section{- To cite this version:}

F. Destandau, A. Nafi. What is the best distribution for pollution abatement efforts? Information for optimizing the WFD Programs of measures. Environmental and Resource Economics, 2010, 46 (3), p. 337 - p. 358. 10.1007/s10640-010-9344-y . hal-00494436

\section{HAL Id: hal-00494436 \\ https://hal.science/hal-00494436}

Submitted on 23 Jun 2010

HAL is a multi-disciplinary open access archive for the deposit and dissemination of scientific research documents, whether they are published or not. The documents may come from teaching and research institutions in France or abroad, or from public or private research centers.
L'archive ouverte pluridisciplinaire HAL, est destinée au dépôt et à la diffusion de documents scientifiques de niveau recherche, publiés ou non, émanant des établissements d'enseignement et de recherche français ou étrangers, des laboratoires publics ou privés. 


\title{
What is the best distribution for pollution abatement efforts?
}

\section{Information for optimizing the WFD Programs of measures.}

\begin{abstract}
The Water Framework Directive (WFD) has mobilized economic theory in order to encourage E.U. Member States to reach desirable environmental water pollution levels by conciliating economic and ecological interests. For this purpose, a stringent standard ("good status") has been set. Nevertheless, it will be possible to relax this standard if it appears that total abatement costs required for reaching this "good status" exceed expected environmental benefits. This ambitious policy updates the issue of the abatement costs and environmental benefits assessment. Concerning the costs, a full discrimination of the abatement effort minimizes the total cost when the impact of polluters changes spatially, while a uniform effort can reach a pollution target in flexible ways. In this case, the increase of the degree of discrimination of the abatement effort is required only if it generates significant positive economies. Our theoretical and empirical results have shown that the discrimination advantage becomes insignificant for either very demanding or very little demanding ecological standards and varies according to the polluters' profile. In the case of “intermediate" standards, efficiency gains become negligible with a restricted number of effort "levels".
\end{abstract}

Keywords: Abatement effort discrimination, Pollution control cost, Water Framework Directive (WFD)

JEL classification: D62, K32, Q52

\section{Introduction}

The American Clean Air act of 1970, and more precisely the introduction of tradeable permits in order to reduce air pollution in USA, and, later, the establishment of the Total Maximum Daily Load procedures in 1992 by the Clean Water Act, encouraged economists to be interested in the allocation of the abatement effort. Even if the equalization of marginal costs of abatement allows a reduction of total emissions based on minimum cost, it doesn't allow reaching ambient standards with minimum cost if the impact of effluents is spatially 
heterogeneous (Montgomery 1972, Tietenberg 1974a et 1974b). Nevertheless, Baumol (1972) and Baumol \& Oates (1988) assert that the equalization of abatement marginal costs can be obtained more easily by a uniform effluent tax rate or by tradeable permits. Concerning the Pigovian tax, little information concerning the costs is required, because the rate can be adjusted according to the observed ambient concentration. As for the minimizing cost allocation presented by Tietenberg and Montgomery, it requires discriminated effluents tax rate or a spatial discrimination of tradeable permits by separated exchange zones or differentiating permits' prices according to the location of buyers and sellers (see Tietenberg 2006). These policies are more demanding to implement, they need more information (see Duggan and Roberts 2002) and could generate acceptability costs (see Bosch and al 2006 for equity problem). We gather these constraints under the generic name: discrimination costs. Thus, because of the presence of discrimination costs, abatement effort discrimination is justified only if it offers a significant reduction of costs. Tietenberg $(1995,2006)$ enumerates the studies that estimate the total cost of abatement for discriminated and uniform allocation. For McGartland (1984) and Atkinson \& Lewis (1974) the reduction of costs is within range of $40 \%$ to $78 \%$ depending on the region, the nature of the pollutant and the standard. However, we don't identify studies dealing with the factors that influence the size of this reduction of cost. Destandau \& Point (2000a, 2000b, 2003) have demonstrated that between full discrimination and uniform abatement effort, there's a range of possible options with a partial discrimination of the abatement effort in gathering the polluters into different effort levels. The discrimination degree changes between both extreme solutions and the discrimination costs increase with the discrimination degree. However, there still remains the issue of factors influencing the total abatement cost variation according to the discrimination degree. The major role played by the cost-benefit analysis in the Water Framework Directive (WFD) has provided the opportunity for examining this issue. 
The WFD has mobilized economic theory permitting Member States not to comply with the "good status" objective for water bodies if there is sufficient evidence that environmental benefits are below the total cost of abatement programs of measures. Yet, in the case of multisource pollution, the total pollution abatement cost required for reaching a certain environmental quality level shall vary according to the distribution of the abatement effort. Therefore, the conclusion of the cost-benefit analysis may be different. Similar to methods employed for assessing environmental benefits, decision-makers will have to accurately define the abatement effort distribution at a Community level. This distribution should be used as a reference for preparing WFD programs of measures. Discriminating the abatement effort increases first-best efficiency by achieving the same level of quality at a reduced cost but also generates discrimination costs.

The purpose of this work was first to identify the conditions under which a uniform distribution of the effort leads to significant under-efficiency, or when it seems interesting overall. Secondly, the aim was to determine which degree of discrimination should be recommended when a discrimination approach seems preferable. The contribution of this analysis is to focus on which factors determine efficiency gain from discriminating among polluters by type, namely when discrimination can be judged to be beneficial and when it isn't beneficial. Section 2 will provide an overview of the Water Framework Directive. In the third section, we present the different distributions of abatement effort. The models are static with several polluters contributing to the concentration of one pollutant in the environment ${ }^{1}$. Section 4 will present the indicators employed for observing efficiency gains as well as our hypothesis regarding effort functions. Sections 5 and 6 are dedicated to our theoretical work, maximum efficiency gains and maximum "absorbed" efficiency gains, respectively for each effort discrimination degree. Prior to the conclusion in section 8 , our theoretical results will be 
tested with an empirical application on a river in the Adour-Garonne basin (France) in section 7.

\section{Water Framework Directive (2000)}

The Water Framework Directive (Directive 2000/60/EC of the European Parliament and Council, $23^{\text {rd }}$ of October 2000) represents a major turning point in the European Water Policy. Firstly, it unifies the objectives of previous Directives which distinctly describe the following issues, though sometimes in a contradictory manner: underground water, surface water, water intended for drinking water supplies, bathing activities, fish and shellfish farming, etc. Secondly, in this Framework Directive, the economic analysis plays a major role in relation to setting ecological objectives and to establishing the means required for achieving them. As regards river pollution reduction, the Directive refers to cost-benefit analysis for setting ambient standards (or ecological objectives) and to the cost-effectiveness analysis for defining the abatement effort distribution. Furthermore, using incentive tools is clearly recommended for achieving these objectives.

In relation to this WFD, river basin, which currently represent the recommended management scale, are broken down into different units: "water bodies", to which are assigned a quality level on a scale from 1 to 5 (i.e. "high status", "good status", "average status", "poor status", "low status"). The quality class assigned to the water body is defined by chemical considerations, biological considerations (for surface water) and quantitative considerations (for underground water). The ecological objectives or ambient standards to be reached were determined after a long consultation process between environmental protection associations, main polluters and water companies. As a result, the "good status" ambient standard was initially set (i.e. quality class 2); it is a stringent ambient standard, which is relatively tolerant regarding anthropologic pressure. Different deadlines have been set for 
achieving the "good status" objective: 2015, 2021 and 2027. It already seems too difficult for some water bodies to achieve this objective by 2015. In order to avoid an environmentalist drift, a correction mechanism has been included in the Directive. An exemption can be granted for certain "water bodies" if there is evidence that costs required for achieving the "good status" objective exceed resulting environmental benefits. Two types of exemptions may be granted: delaying the "good status" achievement deadline (either to 2021 or 2027), or setting a less demanding ambient standard. However, a major coordination effort is required in order to determine methods to assess benefits and costs. Indeed, overestimated costs or underestimated benefits will lead wrongly to a more flexible ecological target. Concerning costs, when pollutants have various sources, the same quality level can be achieved for the natural environment with different abatement effort distributions. Each distribution involves separate total costs for the same ecological outcome. Thus, the distribution of pollution abatement efforts must be clarified as this explanation will be used as a reference in the costbenefit analysis.

\section{The different ways to allocate the abatement effort}

\subsection{DEFINITIONS OF THE ABATEMENT EFFORT}

Several definitions can be given for the abatement effort, or more precisely, different conditions may mean that the abatement effort is the same: the same amount of pollutant recovered or the same pollution abatement cost for instance.

In our study, the abatement effort $E_{x}$ is considered uniform if marginal pollution abatement $\operatorname{costs} c_{x}^{\prime}\left(q_{x}\right)$ are identical for each polluter, where $q_{x}$ is the abated quantity. Indeed a distribution aiming to balance out marginal pollution abatement costs among polluters is achieved by using non-discriminated incentive tools (uniform effluent tax rate for example or tradeable permits without different exchange zones and with a unique permit price). 


$$
\mathrm{E}_{x}=c_{x}^{\prime}\left(q_{x}\right)
$$

\subsection{MINIMUM COST SOLUTION FOR REDUCING AMBIENT POLLUTION}

In the search for the most cost-efficient solution, it seems obvious that the reference program of measures (for each pollutant) must be based on the effort distribution minimizing the sum of abatement costs to achieve an ambient pollution: the good status. However, as demonstrated by Montgomery (1972) and Tietenberg (1974a, 1974b), the pollutants released into the environment are subjected to heterogeneous transformations (transport, dilution, degradation,...). The increase of the pollution concentration $\theta_{x}$ due to an additional unit of emissions, will be different according to the emitter $x$. We denote $\theta_{x}$ the transfer coefficient. We assume that a polluter with the highest transfer coefficients is more «harmful ». For $X$ pollution sources, one of the Kuhn-Tucker conditions mentioned by Tietenberg (2006) to reach the target at minimum cost, with our notations, is:

$$
q_{x} \cdot\left[c_{x}^{\prime}\left(q_{x}\right)-\lambda \cdot \theta_{x}\right]=0 \quad \forall x \in[1, X]
$$

$\lambda$ is an indicator of the weight of the pressure exerted on receptor $y$, in this case the total abatement cost variation when the ambient standard is modified by one unit. With (1), we obtain:

$$
q_{x} \cdot\left[E_{x}-\lambda \cdot \theta_{x}\right]=0 \quad \forall x \in[1, X]
$$

Condition (2) shows that with a sufficiently demanding standard and non-prohibitive abatement costs, the abatement effort shall be proportional to the expression $\lambda \cdot \theta_{x}$. Therefore the effort is proportional to the pressure exerted by the polluter on the ecosystem which is subject to standards. 
We note that the efforts, and then the marginal abatement costs, are equal for efficiency only when each pollution source has the same transfer coefficient. In other words, recalling Tietenberg, the "equal marginal cost" requirement for efficiency is generally incorrect with locational effects.

\subsection{GROUPING POLLUTERS IN EFFORT LEVELS}

Various authors, including Baumol and Oates (1988), have underlined that this type of discriminated policy could require a significant amount of information. It can also generate additional administrative costs (in addition to data search costs), as well as considerable acceptability costs. In order to avoid these discrimination costs, Baumol and Oates propose to standardize the abatement effort, even in the case of different transfer coefficients from one polluter to another.

Faced with the two extreme solutions: a perfectly discriminated effort distribution offering maximum first-best efficiency (minimum total abatement costs) and uniform effort distribution offering minimum discrimination costs, Destandau and Point (2000a, 2000b, 2003) have suggested an intermediate solution: a partially discriminated distribution of the effort. The aim is to determine a good trade off between first-best efficiency and discrimination costs by grouping polluters in $N$ levels of effort ${ }^{2}$. The methodology consists in solving three Problems: the Community Problem, the Allocation Problem and the Complexity Problem. For each discrimination degree $N$ and each groups of polluters $n$, the Community Problem consists in assigning an effort level to $n$.

We denote by $E_{N}^{n}$ the abatement effort common to all polluters from the $n^{\text {th }}$ group. The inversion of the function (1) gives the quantity of abated pollution $q_{x}$ by a polluter $x$ :

$$
q_{x}\left(E_{n}\right)=c_{x}^{\prime-1}\left(E_{N}^{n}\right) \quad \forall x \in n, \forall n \in[1, N] .
$$


Using our notations, and considering that the effluent tax rate in Destandau and Point (2003) is the effort level here (both are equal to the marginal cost), we can rewrite the Destandau and Point (2003) expression as below:

$$
\mathrm{E}_{x}=\mathrm{E}_{N}^{n}=\frac{\lambda(N) \sum_{x \in n} \theta_{x} q_{x}^{\prime}\left(\mathrm{E}_{N}^{n}\right)}{\sum_{x \in n} q_{x}^{\prime}\left(\mathrm{E}_{N}^{n}\right)} \quad \forall x \in n, \forall n \in[1, N], \forall N \in\left[1, N_{\max }\right]
$$

The effort level recommended for each group of polluters is related to the intensity of ecological constraints and to the average intra-group impact of pollutant release in the natural environment. For $N=N_{\max }$, perfectly discriminated effort distribution (at a reduced cost) is determined. $N_{\max }$ will be equal to $X$ if the transfer coefficient is different for each pollution source.

For $N=1$, we obtain the expression of the uniform effort $E_{U}$ :

$$
\mathrm{E}_{x}=\mathrm{E}_{U}=\frac{\lambda(1) \cdot \sum_{x=1}^{X} \theta_{x} \cdot q_{x}^{\prime}\left(\mathrm{E}_{U}\right)}{\sum_{x=1}^{X} q_{x}^{\prime}\left(\mathrm{E}_{U}\right)} \quad \forall x \in[1, X]
$$

The purpose of the Allocation Problem is to define polluter groups that minimize total cost for any possible discrimination degree $N$. The variation of first-best efficiency can thus be observed when the discrimination degree changes. If discrimination costs are known, a simple confrontation with first-best efficiency will enable us to determine the optimal discrimination degree. This is the last step in the methodology: the Complexity Problem.

\section{Methodology}

The study focuses on controlling a single multi-source pollutant whose impact on the natural environment varies according to the localization of effluents. This single pollutant can also be assimilated to a degree of harmfulness linked to the impact of different of different pollutants, 
which are thus comparable such as in the tax basis in Germany. The concentration of this pollutant must not exceed a threshold or standard at a single receptor.

\subsection{RELATIVE FIRST-BEST EFFICIENCY GAINS}

The first-best efficiency gains defines the decrease of total abatement cost when the discrimination degree (or the number of effort groups) increases.

First, we want to know if the discrimination of the abatement effort is really effective. To answer this question, we build a first indicator: the Maximum relative Efficiency Gains (MEG), which measures the relative difference between the total abatement cost of uniform effort $\left(C_{U}\right)$ and perfect discriminated effort $\left(C_{P}\right)$ :

$$
\mathrm{MEG}=\frac{C_{U}-C_{P}}{C_{U}}=1-\frac{C_{P}}{C_{U}}
$$

Once the discrimination seems effective, the purpose is to know which discrimination degree is sufficient. Then, a second indicator: the Absorbed Efficiency Gains (AEG) estimates the percentage of MEG that is absorbed by switching from a uniform distribution to a distribution among $N$ abatement effort levels ( $\left.\mathrm{AEG}_{\mathrm{U}-\mathrm{N}}\right)$.

$$
\mathrm{AEG}_{\mathrm{U}-\mathrm{N}}=\frac{C_{U}-C_{N}}{C_{U}-C_{P}}
$$

\subsection{POLLUTION ABATEMENT EFFORT FUNCTION}

As specified above (1), the abatement effort will be determined by the type of marginal cost function selected. It will be referred to the effort function. Two types of effort functions will be considered, first a linear trend:

Linear effort function: $\quad E_{x}=\frac{q_{x}}{e f f_{x}}+F_{x} \quad \forall x \in[1, X], q_{x} \in\left[0, q_{x}^{\max }\right]$ 
Each polluter $x$ is characterized by fixed costs $F_{x}$, by an efficiency parameter eff $x$ (the polluter can abate at a lower cost when the parameter is high), and by a maximum quantity of pollution which can be abated, corresponding to the quantity of pollution produced by $x: q_{x}^{\max }$. Indeed, a linear marginal cost function implies the existence of a maximum abatement effort that can cancel out the emissions. In this case, we speak about large-scale or small-scale polluters depending on the value of $q_{x}^{\max }$.

We also use convex marginal abatement cost functions which is a widely used hypothesis in the literature. This hypothesis considers that the cost of the integral abatement of the produced pollution is infinite.

$$
\text { Convex effort function: } E_{x}=-\left(\frac{1}{e f f_{x}}\right) \ln \left(1-\frac{q_{x}}{q_{x}^{\max }}\right) \quad \forall x \in[1, X]
$$

Function (8) was proposed by Barrett (1994). It integrates the hypothesis often encountered in the literature (i.e. positive marginal abatement costs, increasing with an increasing rate tending towards $+\infty$ for an abated pollution converging towards a maximum $q^{\max }$ ).

It will be possible for any polluter $x$ to be identified by a vector $\left(\theta_{x}, q_{x}^{\max }\right.$,eff $)$ i.e. by its harmfulness, size and efficiency. In this case, polluter's ability to reduce its effluents with a minimum cost doesn't depend only on the parameter $e f f_{x}$, because the slope of effort's curve depends on both the parameters $q_{x}^{\max }$ and $e f f_{x}$ and also on the standard $\bar{Q}$, since the slope increases with the abated quantity. Thus, a small polluter (low $q_{x}^{\max }$ ) that is efficient (high $e f f_{x}$ ) could abate the first units of pollutant in a cheap way, but in expensive way for the last ones. With high $\theta_{x}, q_{x}^{\max }$ and $e f f_{x}$ coefficients, the polluter will have more chance to reduce the pollution in the environment at a minimum cost. 


\section{Maximum efficiency gains}

\subsection{MEG WITH A LINEAR EFFORT FUNCTION}

$\mathrm{X}$ polluters contribute to the pollution concentration at the receptor level. The strict compliance with an ecological standard requires the removal of a concentration $\bar{Q}$ from the environment. In this case, the abatement effort is given by:

$$
\bar{Q}=\sum_{x=1}^{X} \theta_{x} \cdot q_{x}
$$

With the linear effort function (7), expression (9) becomes:

$$
\bar{Q}=\sum_{x=1}^{X} \theta_{x} \cdot e f f_{x} .\left(\mathrm{E}_{x}-F_{x}\right)
$$

The following expression ${ }^{4}$ is determined from expressions (2) ${ }^{3}$ and (4) (as a uniform distribution and perfectly discriminated distribution):

$$
\text { Uniform effort }^{5}: \bar{Q}=\sum_{x=1}^{X} \theta_{x} \cdot e f f_{x} \cdot\left(\lambda_{U} \cdot \frac{\sum_{x=1}^{X} \theta_{x} \cdot e f f_{x}}{\sum_{x=1}^{X} e f f_{x}}-F_{x}\right)
$$

Perfectly discriminated effort: $\bar{Q}=\sum_{x=1}^{X} \theta_{x} . e f f_{x} .\left(\lambda_{P} . \theta_{x}-F_{x}\right)$

Based on $\lambda_{U}$ and $\lambda_{P}$, respectively the "weight" of the standard as a uniform distribution and the perfectly discriminated distribution of the effort, the following expression can be written:

$$
\begin{aligned}
& \text { Uniform effort: } \lambda_{U}=\left[\bar{Q}+\sum_{x=1}^{X} \theta_{x} \cdot \text { eff } f_{x} \cdot F_{x}\right] \cdot \frac{\sum_{x=1}^{X} e f f_{x}}{\left(\sum_{x=1}^{X} e f f_{x} \cdot \theta_{x}\right)^{2}} \\
& \text { Perfectly discriminated effort: } \lambda_{P}=\left[\bar{Q}-\sum_{x=1}^{X} \theta_{x} \cdot e f f_{x} \cdot F_{x}\right] \cdot \frac{1}{\sum_{x=1}^{X} e f f_{x} \cdot \theta_{x}^{2}}
\end{aligned}
$$

By integrating theses terms from 0 to $\bar{Q}$, we define the total cost of abatement $C_{P}$ for the discriminated effort and $C_{U}$ for the uniform effort. 


$$
\begin{aligned}
& C_{P}=\int_{0}^{\bar{Q}}\left[Q+\sum_{x=1}^{X} \theta_{x} \cdot e f f_{x} \cdot F_{x}\right] \cdot \frac{1}{\sum_{x=1}^{X} e f f_{x} \cdot \theta_{x}^{2}} d Q=\left[\bar{Q}^{2}+\bar{Q} \cdot \sum_{x=1}^{X} \theta_{x} \cdot e f f_{x} \cdot F_{x}\right] \cdot \frac{1}{\sum_{x=1}^{X} e f f_{x} \cdot \theta_{x}^{2}} \\
& C_{U}=\int_{0}^{\bar{Q}}\left[Q+\sum_{x=1}^{X} \theta_{x} \cdot e f f_{x} \cdot F_{x}\right] \cdot \frac{\sum_{x=1}^{X} e f f_{x}}{\left(\sum_{x=1}^{X} e f f_{x} \cdot \theta_{x}\right)^{2}} d Q=\left[\bar{Q}^{2}+\bar{Q} \cdot \sum_{x=1}^{X} \theta_{x} \cdot e f f_{x} \cdot F_{x}\right] \cdot \frac{\sum_{x=1}^{X} e f f_{x}}{\left(\sum_{x=1}^{X} e f f_{x} \cdot \theta_{x}\right)^{2}}
\end{aligned}
$$

Thus, the following expression is obtained:

$$
\mathrm{MEG}=1-\frac{\left(\sum_{x=1}^{X} e f f_{x} \cdot \theta_{x}\right)^{2}}{\sum_{x=1}^{X} e f f_{x} \sum_{x=1}^{X} e f f_{x} \cdot \theta_{x}^{2}}
$$

The above expression (10) indicates that with linear effort functions (unlimited), the maximum efficiency gains (MEG) do not depend on the Standard ${ }^{6}$. Indeed, the trend of the effort curves is independent from the standard constraint.

The expression (10) confirms that when the polluters have the same transfer coefficient $\theta_{x}$, the relative efficiency gains are null. In this case, the uniform effort (equalization of the marginal abatement cost) is the solution with a minimum cost. Symmetrically, the relative efficiency gains increase when the transfer coefficients are more heterogeneous. Indeed, if the polluters are equally efficient, expression (10) becomes:

$$
\mathrm{MEG}=1-\frac{\left(\sum_{x=1}^{X} \theta_{x}\right)^{2}}{X \sum_{x=1}^{X} \theta_{x}^{2}}=1-\frac{\sum_{x=1}^{X} \theta_{x} \cdot\left(\sum_{x=1}^{X} \theta_{x} / X\right)}{\sum_{x=1}^{X} \theta_{x}^{2}}=1-\frac{X \bar{\theta}^{2}}{\sum_{x=1}^{X} \theta_{x}^{2}}=1-\frac{\bar{\theta}^{2}}{\sum_{x=1}^{X} \theta_{x}^{2} / X}
$$

By quantifying the heterogeneity of the transfer coefficients by the variance:

$$
\operatorname{Var}\left(\theta_{x}\right)=\frac{\sum_{x=1}^{X}\left(\theta_{x}-\bar{\theta}\right)^{2}}{X}=\frac{\sum_{x=1}^{X} \theta_{x}^{2}}{X}-\bar{\theta}^{2}
$$

we find :

$$
\mathrm{MEG}=1-\frac{\overline{\boldsymbol{\theta}}_{x}}{\operatorname{Var}\left(\boldsymbol{\theta}_{x}\right)+\overline{\boldsymbol{\theta}}_{x}}
$$


Note that more heterogeneity (high variance) in transfer coefficients increases the MEG, and thus the interest to discriminate the abatement effort.

In order to understand how the MEG evolve according to the profiles of polluters, we assess the MEG with two polluters profiles, one considering the most harmful polluter as the most efficient: $\mathrm{MEG}_{++}$, the other one considering the most harmful polluter as the least efficient: $\mathrm{MEG}_{++\cdot}$

- We assume that the harmfulness is an increasing linear function of $\mathrm{x}$ : $\theta_{x}=\theta_{(x)}=\alpha \cdot x \quad \forall x \in[1, X], \alpha \in \Re_{+}^{*}$.

The efficiency is an increasing function of $x$ to calculate $\mathrm{MEG}_{++}$: eff $f_{x}=e f f_{(x)}=\beta . x \quad \forall x \in[1, X] \quad, \quad \beta \in \mathfrak{R}_{+}^{*} \quad$ and decreasing to calculate MEG $_{+-}$: eff $f_{x}=e f f_{(x)}=\beta \cdot(X-x+1) \quad \forall x \in[1, X], \beta \in \mathfrak{R}_{+}^{*}$.

We have:

$\mathrm{MEG}_{++}=1-\frac{\left(\sum_{x=1}^{X} e f f_{x} \cdot \theta_{x}\right)^{2}}{\sum_{x=1}^{X} e f f_{x} \sum_{x=1}^{X} e f f_{x} \cdot \theta_{x}^{2}}=1-\frac{\alpha^{2} \beta^{2}\left(\sum_{x=1}^{X} x^{2}\right)^{2}}{\alpha^{2} \beta^{2} \sum_{x=1}^{X} x \sum_{x=1}^{X} x^{3}}$

$=1-\frac{[X(X+1)(2 X+1) / 6]^{2}}{[X(X+1) / 2]^{*}\left[X^{2}(X+1)^{2} / 4\right]}=1-\frac{8}{36} \cdot \frac{X^{2}(X+1)^{2}(2 X+1)^{2}}{X^{3}(X+1)^{3}}$

$=1-\frac{2}{9} \cdot \frac{(2 X+1)^{2}}{X(X+1)}$

and,

$$
\begin{aligned}
& \mathrm{MEG}_{+-}=1-\frac{\left(\sum_{x=1}^{X} e f f_{x} \cdot \theta_{x}\right)^{2}}{\sum_{x=1}^{X} e f f_{x} \sum_{x=1}^{X} e f f_{x} \cdot \theta_{x}^{2}}=1-\frac{\alpha^{2} \beta^{2}\left(\sum_{x=1}^{X}(X-x+1) \cdot x\right)^{2}}{\alpha^{2} \beta^{2} \sum_{x=1}^{X}(X-x+1) \sum_{x=1}^{X}(X-x+1) \cdot x^{2}} \\
& =1-\frac{\left[(X+1) \sum_{x=1}^{X} x-\sum_{x=1}^{X} x^{2}\right]^{2}}{\left[\sum_{x=1}^{X}(X+1]-\sum_{x=1}^{X} x\right]^{*}\left[(X+1) \sum_{x=1}^{X} x^{2}-\sum_{x=1}^{X} x^{3}\right]} \\
& =1-\frac{\left[X(X+1)^{2} / 2-X(X+1)(2 X+1) / 6\right]^{2}}{[X(X+1)-X(X+1) / 2] *\left[X(X+1)^{2}(2 X+1) / 6-X^{2}(X+1)^{2} / 4\right]}
\end{aligned}
$$


$=1-\frac{24}{36} \cdot \frac{\left[3 X(X+1)^{2}-X(X+1)(2 X+1)\right]^{2}}{[2 X(X+1)-X(X+1)]^{*}\left[2 X(X+1)^{2}(2 X+1)-3 X^{2}(X+1)^{2}\right]}$

$=1-\frac{2}{3} \cdot \frac{[X(X+1)(X+2)]^{2}}{X(X+1) X(X+1)^{2}(X+2)}=1-\frac{2}{3} \cdot \frac{(X+2)}{(X+1)}$

So, $\mathrm{MEG}_{++}$will lower than $\mathrm{MEG}_{+-}$when:

$$
\begin{aligned}
& 1-\frac{2}{9} \cdot \frac{(2 X+1)^{2}}{X(X+1)}<1-\frac{2}{3} \cdot \frac{(X+2)}{(X+1)} \quad \Leftrightarrow \quad \frac{2}{9} \cdot \frac{(2 X+1)^{2}}{X(X+1)}>\frac{2}{3} \frac{(X+2)}{(X+1)} \\
& \Leftrightarrow \quad \frac{(2 X+1)^{2}}{X}>3 \cdot(X+2) \quad \Leftrightarrow \quad X^{2}-2 X+1>0 \\
& \Leftrightarrow \quad(X-1)^{2}>0 \Leftrightarrow \quad X \neq 1
\end{aligned}
$$

Then, for more than one polluter, the MEG is low if the most efficient polluters are the most harmful. In this case, the discrimination is not interesting.

A polluter that is both efficient to abate and harmful will be able to remove a large part of pollution from the environment at a minimum cost. Otherwise, the effort of a polluter that is less efficient and less harmful, will have a low impact on the environment. It seems that the MEG and thus the interest for discrimination, is low when the ability to reduce pollution is uneven among polluters.

Figure 1 illustrates the individual abatement costs fall (+) and growth (-) of polluters A and $\mathrm{B}$, when switching from a uniform effort to a discriminated effort. The left-hand side of Figure 1 shows the case where the most efficient polluter B (lower slope) is the most harmful $\left(E_{B}\right.$ upper than $\left.E_{A}\right)$, the right-hand side is the opposite. In both cases, we can see that the most harmful polluter ( $\mathrm{B}$ in the left-hand side and $\mathrm{A}$ in the right-hand side of the diagram) increases its costs when the allocation becomes discriminated, as opposed to the least harmful polluter. Moreover, when the slope of the abatement marginal cost is low, an effort modification as a 
high impact on the abatement, and thus, on the costs. On the contrary, the more important the slope is, the lower is the impact.

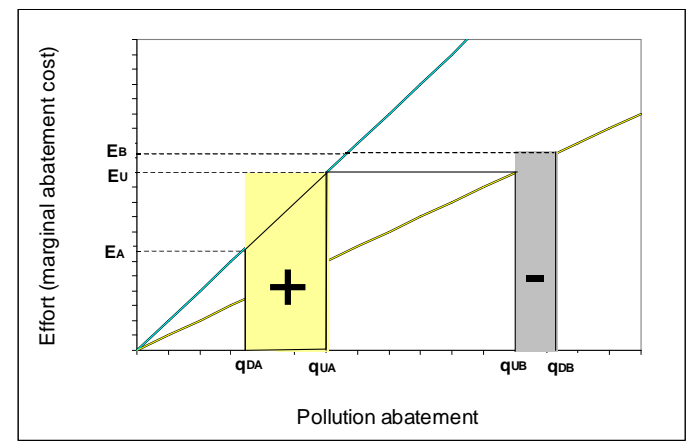

The most efficient $(B)$ is more harmful

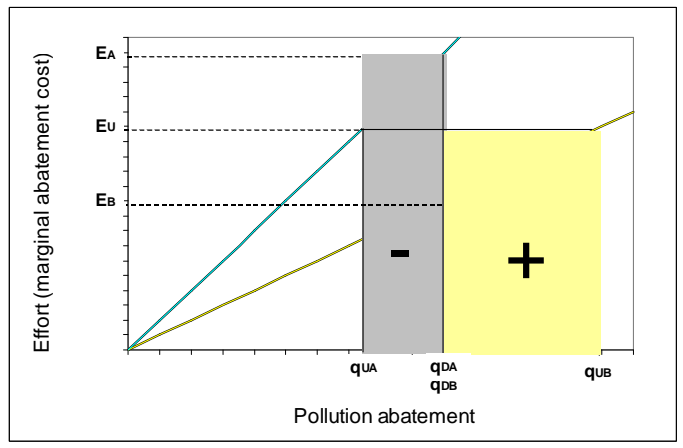

The most efficient $(B)$ is less harmful

Figure 1. Decreasing (+) and increasing (-) costs when we move from uniform to discriminated effort allocation

As a result, the MEG are higher when the polluter that reduces its costs (the least harmful polluter) when it switches to a discriminated allocation, has a lower marginal cost slope (most efficient polluter), and also, when the most harmful polluter is the least efficient (right-hand side of the Figure 1).

\subsection{MEG WITH A BARRETT-TYPE EFFORT FUNCTION}

Section 5.1 has helped identifying which polluters' characteristics influence the level of maximum efficiency gains. The present section investigates the impact of the convexity of effort functions on efficiency gain variation.

Expression (9) concerning the saturation of the ecological standard is rewritten with a Barrett function (8):

$$
\bar{Q}=\sum_{x=1}^{X} \theta_{x} \cdot q_{x}^{\max }\left(1-\exp ^{-e f f_{x} \cdot \mathrm{E}_{x}}\right)
$$

The following expression is determined from expressions $(2)^{3}$ and (4) as a uniform and perfectly discriminated distribution. The simulation was carried out using the Excel Solver tool: 
Uniform effort ${ }^{7}: \bar{Q}=\sum_{x=1}^{X} \theta_{x} \cdot q_{x}^{\max } \cdot\left(1-\exp ^{e f f_{x} \cdot \lambda_{U} \cdot \bar{\theta}}\right)$, where $\bar{\theta}=\frac{\sum_{x=1}^{X} \theta_{x} \cdot e f f_{x} \cdot q_{x}^{\max } \cdot \exp ^{\left(-e f f_{x} \cdot \mathrm{E}_{U}\right)}}{\sum_{x=1}^{X} e f f_{x} \cdot q_{x}^{\max } \cdot \exp ^{\left(-e f f_{x} \cdot \mathrm{E}_{U}\right)}}$

Perfectly discriminated distribution: $\bar{Q}=\sum_{x=1}^{X} \theta_{x} \cdot q_{x}^{\max } \cdot\left(1-\exp ^{-e f f_{x} \cdot \lambda_{p} \cdot \theta_{x}}\right)$

The expression (11) above is difficult to inverse in order to isolate $\lambda_{u}$ and $\lambda_{D}$, as we did with the linear effort function. Moreover, as described before, the MEG depends on the relative slopes of the effort curves, which are jointly linked to all the parameters in the case of convex functions. This inversion is obtained with a simulation ${ }^{8}$.

To observe the evolution of MEG according to the different parameters, we consider 2 polluters $\mathrm{A}$ and $\mathrm{B}$. Each polluter is characterized by its size $q_{x}^{\max }$, efficiency eff $f_{x}$ and harmfulness $\theta_{x}$.

- Four cases are considered:

CASE 1: The large-scale polluter is more efficient and more harmful.

CASE 2: The large-scale polluter is more efficient and less harmful.

CASE 3: The large-scale polluter is less efficient and more harmful.

CASE 4: The large-scale polluter is less efficient and less harmful.

- The selected values are:

Size: $q_{x}^{\max }=10$ (Large-scale) or $q_{x}^{\max }=5$ (Small-scale)

Efficiency: $e f f_{x}=1$ (more efficient) or eff $f_{x}=0.5$ (less efficient)

Harmfulness: $\theta_{x}=1$ (more harmful) or $\theta_{x}=0.5$ (less harmful)

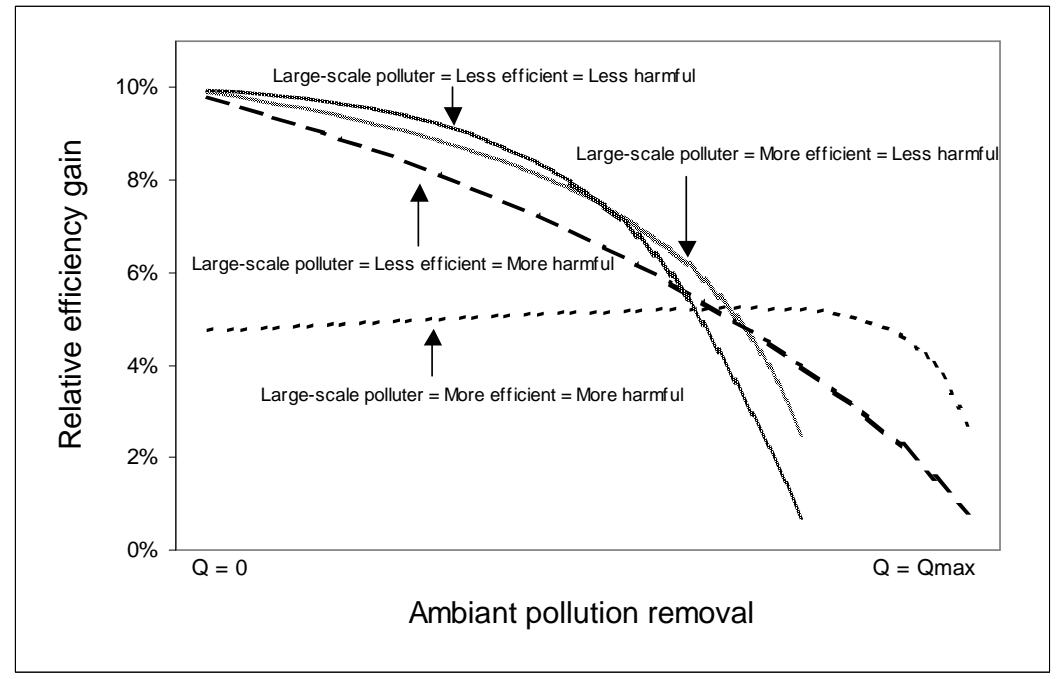

Figure 2. MEG according to the polluters' profile 
Figure 2 indicates that the evolution of maximum efficiency gains takes several forms depending on the characteristics of the polluters. Nevertheless, in spite of theses differences, we can extract some results from this diagram.

First, whatever the polluter's profile, the efficiency gains become insignificant for extremely demanding standards. The justification for this result is comparable to Weitzman's theory (1974) where he recommended using a price or quantity control approach according to the slope of cost and benefit curves. When the standard is very demanding, the abatement effort is very high, inducing a very strong slope of the effort function. Thus, switching from a uniform effort distribution to a discriminated distribution will have very little impact on the quantities of pollutant released and therefore on related costs.

As described before on the polluters profiles, the ability to reduce the effluents with minimum cost varies strongly according to the values of model's parameters. It explains why the evolution of MEG is different according to the polluter's profile (Figure 2). However, even if three of these curves have a similar shape, one profile differs amongst them: Case 1. Indeed, we note that the MEG remains moderate, whatever the level of the standard constraint, when polluters able to reduce their effluents at a minimum cost ( $q_{x}^{\max }$ and $e f f_{x}$ high) are the most harmful. Here, we recognize the results given by the linear functions. However, we can see that for strongly demanding standards, the MEG is higher for this profile (case 1). As shown before, the MEG tends to 0 when all polluters become inefficient to reduce water pollution. This inefficiency comes later (for more demanding standards) for polluters which are both "large", efficient and harmful.

The opportunity to discriminate or not the abatement effort will truly depend on "absolute" efficiency gains, i.e. the difference between total abatement costs as a discriminated effort and uniform effort, but also on discrimination costs which are not the 
subject of our study. However, studying maximum efficiency gains has enabled the collection of significant information for fuelling this discussion. Regardless of the polluters' profile, the discrimination has no significant purpose if the standard is very little demanding or, on the other hand, if it is very demanding. In the former case, this is due to low absolute costs, and in the latter case, to the convexity of cost functions.

Result of section 5. With linear effort functions (unlimited), maximum efficiency gains (MEG) do not depend on the ecological standard ${ }^{4}$. MEG increase when the transfer coefficients are more heterogeneous. This result is intensified if the most harmful polluters are the least efficient. With convex effort functions, maximum efficiency gains become insignificant as the standard becomes more demanding. The discrimination is therefore not very interesting with either a very demanding or very little demanding standard (due to low absolute costs).

\section{Maximum "absorbed" efficiency gains}

This section focuses on the partial discrimination of the abatement effort. For each level of effort $N$, the aim is to define polluter groups and their respective abatement effort.

\subsection{AEG $_{U-N}$ WITH A LINEAR EFFORT FUNCTION}

The Community Problem provides the abatement effort for the $n^{\text {th }}$ polluter group.

Results [3] and [6] provide the value of the effort level for the $N^{\text {th }}$ group in the case of a degree of discrimination $N^{5}$ :

$$
E_{N}^{n}=\lambda_{N} \cdot \frac{\sum_{x \in n} \theta_{x} \cdot e f f_{x}}{\sum_{x \in n} e f f_{x}} \quad \forall n \in[1, N] ; \forall N \in[1,+\infty[
$$


If polluters are equally efficient, the effort level will be proportional to the average transfer coefficient of polluters of the group. Otherwise, the transfer coefficient of the most efficient polluters would have the greatest influence on the effort level of the group.

In order to improve understanding on the way groups are determined, and gather information on the trend of efficiency gains, we consider the following hypothesis on a neutral profile of polluter:

Hypothesis 6.2: A continuum of polluters ranked in increasing order of harmfulness is assumed on segment $\left.] 0, x_{\max }\right]$. Thus, grouping polluters in effort levels consists in positioning "boundaries" on $\left.] 0, x_{\max }\right]$. Each group $n$ will be limited by segment $\left.] B_{\mathrm{inf}}^{n}, B_{\mathrm{sup}}^{n}\right]$. We assume that harmfulness is a linear increasing function $\theta_{(x)}$ on $\left.] 0, x_{\max }\right]$, in such way that the harmfulness $\theta_{x}=\theta_{(x)}$ of a polluter $x$ will be equal to $\theta . x$ (parameter $\theta$ being a constant). Last, we consider similar cost functions for all polluters, that is to say constant parameters eff and $q^{\max }$ and fixed costs $F$ nulls.

According to the hypothesis 6.2 above, the expression [12] becomes:

$$
\mathrm{E}_{N}^{n}=\lambda_{N} \cdot \theta \cdot\left[\frac{B_{\text {inf }}^{n}+B_{\text {sup }}^{n}}{2}\right] \quad \forall n \in[1, N] ; \forall N \in[1,+\infty[
$$

According to the hypothesis 6.2, the Allocation Problem provides groups of a similar scale. In order to demonstrate it, we rewrite the saturation condition of the standard (9) with these hypothesis. For two groups separated by a boundary B, the condition becomes:

$$
\bar{Q}=\int_{0}^{B} \theta \cdot x . e f f . \mathrm{E}_{2}^{1} d x+\int_{B}^{x_{\max }} \theta \cdot x . e f f . \mathrm{E}_{2}^{2} d x
$$

By integrating expression (13): $\bar{Q}=\int_{0}^{B} \theta \cdot x \cdot$ eff $\cdot \lambda_{2} \cdot \theta \cdot \frac{B}{2} d x+\int_{B}^{x_{\max }} \theta \cdot x \cdot$ eff $\cdot \lambda_{2} \cdot \theta \cdot \frac{\left(x_{\max }-B\right)}{2} d x$

$$
\Leftrightarrow \quad \bar{Q}=\theta \cdot e f f \cdot \lambda_{2} \cdot \theta \cdot \frac{B}{2} \cdot \frac{B^{2}}{2}+\theta \cdot e f f \cdot \lambda_{2} \cdot \theta \cdot \frac{\left(x_{\max }-B\right)}{2} \cdot \frac{\left(x_{\max }-B\right)^{2}}{2}
$$




$$
\begin{array}{ll}
\Leftrightarrow & \bar{Q}=\lambda_{2} \cdot \frac{\theta^{2} \cdot e f f}{4} \cdot\left[B^{3}+\left(x_{\max }-B\right)^{3}\right] \\
\Leftrightarrow & \lambda_{2}=\frac{4 \bar{Q}}{\theta^{2} \cdot \text { eff } \cdot\left[B^{3}+\left(x_{\text {max }}-B\right)^{3}\right]}
\end{array}
$$

The cost function (according to the quantities of pollution removed) is convex, so the total cost will be minimum for minimum marginal cost $\lambda_{2}$.

$$
\begin{aligned}
& \frac{\partial \lambda_{2}}{\partial B}=-\frac{12 \cdot \bar{Q}}{\theta^{2} \cdot e f f} \cdot\left[B^{2}-\left(x_{\max }-B\right)^{2}\right] \cdot\left[B^{3}+\left(x_{\max }-B\right)^{3}\right]^{-2}=0 \\
& \Leftrightarrow \quad B^{2}-\left(x_{\max }-B\right)^{2} \quad=0 \quad \Leftrightarrow \quad \mathrm{B}=\frac{x_{\max }}{2}
\end{aligned}
$$

We can easily check that the second derivative $\partial^{2} \lambda_{2} / \partial B^{2}$ is positive.

Thus, for a discrimination of degree 2, the boundary separating the two groups (or effort levels) is at $\frac{x_{\max }}{2}$. By recurrence, we deduct that for a degree 3 discrimination, boundaries are positioned at $\frac{x_{\max }}{3}$ and $\frac{2 x_{\max }}{3}$, and thus, for a discrimination of degree $N$, the $n^{\text {th }}$ group includes polluters located on the segment :

$$
] \frac{n-1}{N} x_{\max }, \frac{n}{N} x_{\max }\right] \quad \forall n \in[1, N] ; \forall N \in[1,+\infty[
$$

By substituting expression (13), the following expression is obtained:

$$
\mathrm{E}_{N}^{n}=\lambda_{N} \cdot \theta \cdot \frac{(2 n-1)}{2 N} \cdot x_{\max } \quad \forall n \in[1, N] ; \forall N \in[1,+\infty[
$$

The saturation of the standard is written (in the general case) as follows:

$$
\bar{Q}=\sum_{n=1}^{N} \int_{B_{\mathrm{inf}}^{n}}^{B_{\text {sip }}^{n}} \theta_{x} \cdot q_{x} d x \quad \forall N \in[1,+\infty[
$$

With results (15), (8), (16) and the hypothesis 6.2 the following expression is obtained:

$$
\bar{Q}=\lambda_{N} \cdot \frac{e f f \cdot \theta^{2} \cdot x_{\max }}{N} \cdot \sum_{n=1}^{N}(2 n-1) \int_{(n-1) x_{\max } / N}^{n x_{\max } / N} x d x \quad \forall N \in[1,+\infty[
$$




$$
\begin{array}{lll}
\Leftrightarrow & \bar{Q}=\lambda_{N} \cdot \frac{e f f \cdot \theta^{2} \cdot x_{\max }^{3}}{2 N^{3}} \cdot \sum_{n=1}^{N}(2 n-1)^{2} & \forall N \in[1,+\infty[ \\
\Leftrightarrow & \bar{Q}=\lambda_{N} \cdot \frac{e f f \cdot \theta^{2} \cdot x_{\max }^{3} \cdot\left(4 N^{2}-1\right)}{6 N^{2}} & \forall N \in[1,+\infty[ \\
\Leftrightarrow & \lambda_{N}=\frac{\bar{Q} \cdot 6 N^{2}}{e f f \cdot \theta^{2} \cdot x_{\max }^{3} \cdot\left(4 N^{2}-1\right)} & \forall N \in[1,+\infty[
\end{array}
$$

Thus, by integrating $\lambda_{N}(Q)$ from 0 to $\bar{Q}$, the total abatement $\operatorname{cost} C_{N}$ for a discrimination of degree $N$ is obtained :

$$
C_{N}=\int_{0}^{\bar{Q}} \lambda_{N}(Q) d Q=\frac{\bar{Q}^{2}}{e f f \cdot \theta^{2} \cdot x_{\max }^{3}} \cdot \frac{3 N^{2}}{4 N^{2}-1} \quad \forall N \in[1,+\infty[
$$

It can be noted that only the right-hand term $\frac{3 N^{2}}{4 N^{2}-1}$ depends on discrimination degree $N$.

Thus:

$$
\mathrm{AEG}_{\mathrm{U}-\mathrm{N}}=\frac{C_{U}-C_{N}}{C_{U}-C_{P}}=\frac{4 N^{2}-4}{4 N^{2}-1}
$$

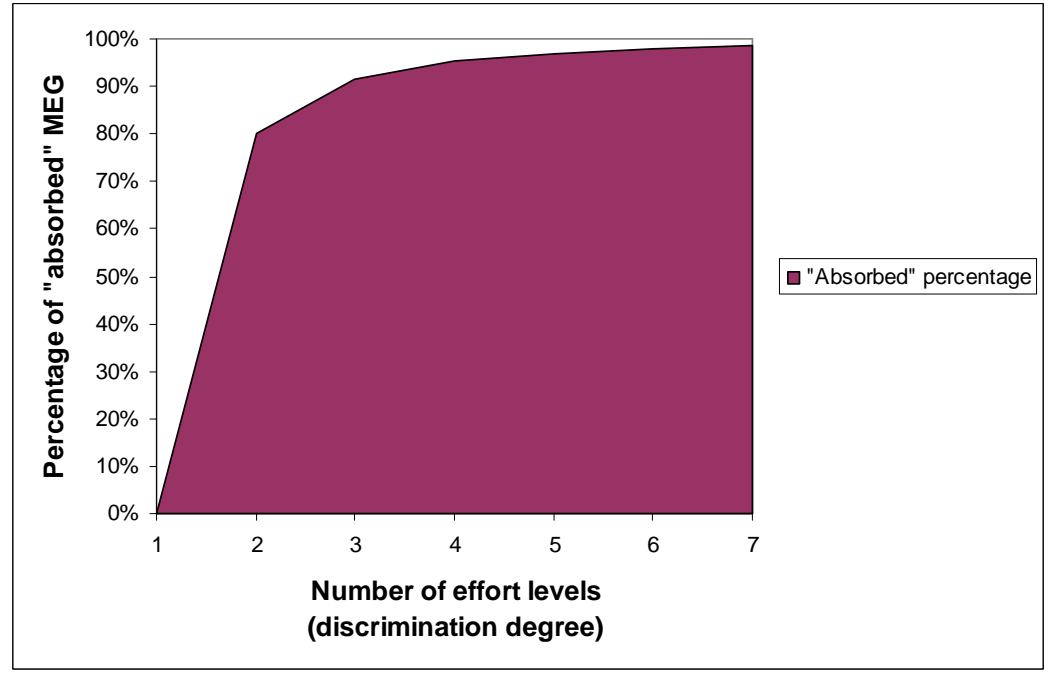

Figure 3. Percentage of "absorbed" MEG for each discrimination degree $\mathrm{N}$

As shown by figure 3, switching from a uniform effort distribution with two effort levels enables to absorb $80 \%$ of maximum efficiency gains, $91.4 \%$ with three effort levels, $95.2 \%$ with four effort levels, etc... It can be noted that with few groups, nearly the same first-best efficiency is obtained as with an infinity of groups (perfectly discriminated effort). 


\subsection{AEG $_{U-\mathrm{N}}$ WITH A BARRETT-TYPE EFFORT FUNCTION}

With a Barrett function $(8)^{7}$, the expression (12) becomes:

$$
E_{N}^{n}=\lambda_{N} \cdot \frac{\sum_{x \in n} \theta_{x} \cdot e f f_{x} \cdot q_{x}^{\max } \cdot \exp ^{-e f f_{x} \cdot E_{x}}}{\sum_{x \in n} e f f_{x} \cdot q_{x}^{\max } \cdot \exp ^{-e f f_{x} \cdot E_{x}}} \quad \forall n \in[1, N] ; \forall N \in[1,+\infty[
$$

With the same hypothesis 6.2, the Community Problem remains the same as with a linear effort function (14).

A "first" breakdown will be analyzed when switching from a uniform distribution to a discrimination of degree 2 . Both effort "groups" are separated on $\left.] 0, x_{\max }\right]$ by boundary B. The saturation condition of the standard becomes (with hypothesis 6.2):

$$
\begin{aligned}
& \bar{Q}=\int_{0}^{B} \theta \cdot x \cdot q^{\max } \cdot\left(1-\exp ^{-e f f \cdot E_{2}^{1}}\right) d x+\int_{B}^{x_{\max }} \theta \cdot x \cdot q^{\max } \cdot\left(1-\exp ^{-e f f_{(x)} \cdot E_{2}^{2}}\right) d x \\
& \Leftrightarrow \frac{2 \bar{Q}}{\theta \cdot q^{\max }}=\left(1-\exp ^{-e f f \cdot E_{2}^{1}}\right) \cdot B^{2}+\left(1-\exp ^{-e f f \cdot E_{2}^{2}}\right) \cdot\left(x_{\max }-B\right)^{2} \\
& \text { with } E_{2}^{1}=\lambda_{2} \cdot \theta \cdot \frac{B}{2} \quad \text { et } E_{2}^{2}=\lambda_{2} \cdot \theta \cdot \frac{B+x_{\max }}{2}
\end{aligned}
$$

The left-hand expression, $\frac{2 \bar{Q}}{\theta \cdot q^{\max }}$, refers to the intensity of the standard constraint. Thus, the standard will become more demanding if $\bar{Q}$ increases, but also if $\theta$ and/or $q^{\max }$ decrease.

As in section 5.2 above, we use a simulation to observe the role of the standard constraint on the relative efficiency gains, here the efficiency gains when we move from a uniform effort to a discrimination degree 2 . We consider the following parameters: eff $=\theta=q^{\max }=x_{\max }=1$. We obtain Figure 4. 


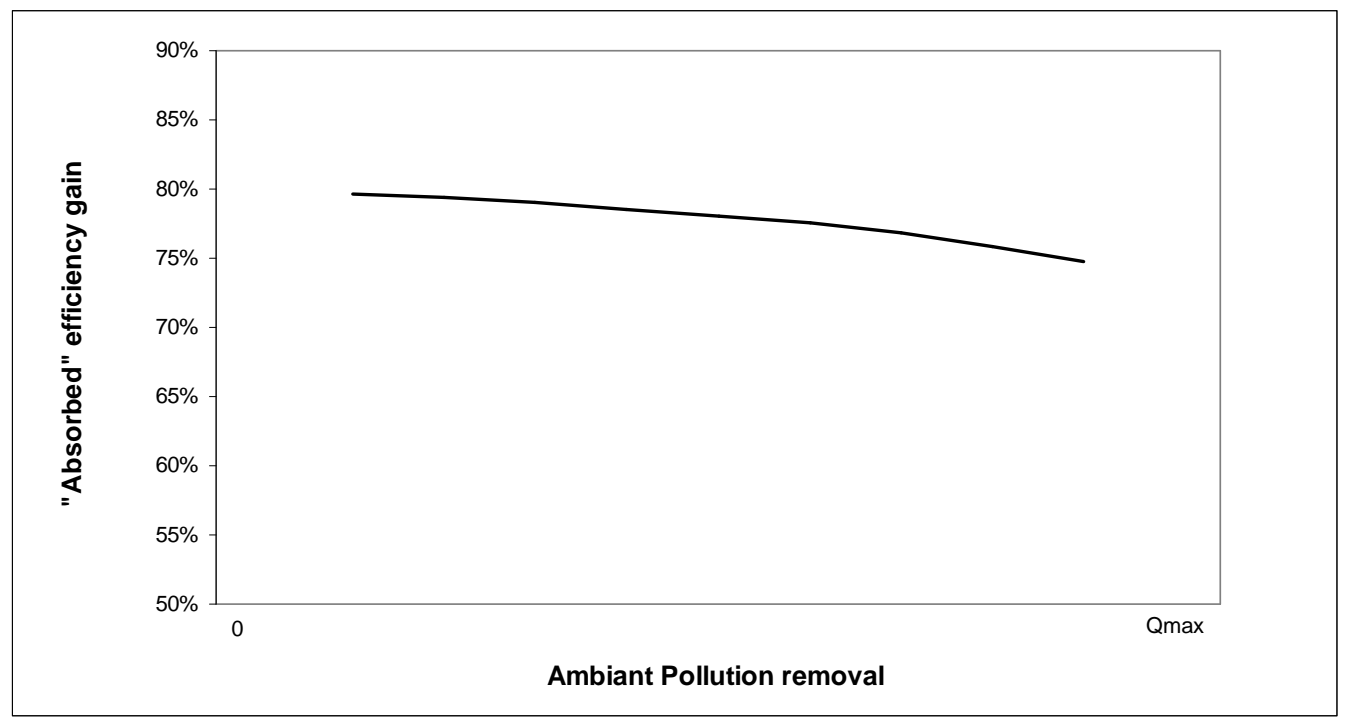

Figure 4. "Absorbed" maximum efficiency gains with 2 effort levels

In accordance with the results obtained with a linear effort function, we find that the transition from a uniform distribution of the abatement effort to a distribution into 2 groups allows the absorption of about $80 \%$ of MEG. However, as shown in Figure 4, this absorption rate decreases slightly for more demanding standards ${ }^{8}$. As explained in section 5.2 , this result indicates that for very demanding standards, the effort function slope is very important, which reduces the effectiveness of discrimination.

Result of section 6: "Absorbed" maximum efficiency gains will depend on polluters' characteristics and the intensity of the standard constraint. However, regardless of the profile, nearly all MEG are absorbed with little effort levels.

\section{Empirical Study}

In this section, a simulation with actual data is presented. Within the framework of the WFD, the abatement effort must allow the achievement of the good status on overall water bodies, and can deal with numerous polluters. Unlike the previous sections, the ecological goal aims to achieve a pollution standard (and not a pollution quantity to abate) for an important number of receptors. 


\subsection{PRESENTATION OF THE CASE STUDY AND SELECTED HYPOTHESIS}

This empirical study focuses on organic pollution of the Isle river in the Adour-Garonne river basin (France), called the Isle River. First-best efficiency gain variations are observed by modifying the abatement effort distribution for different standards which are to be respected over the entire river and no longer at a single receptor point. Polluters are mostly industries and local authorities, which pay a pollution tax to the Adour-Garonne water Agency. 70 polluters 25 different towns are spread out along the river from. For all of these polluters, a Barrett-type abatement effort function has been chosen with an identical eff $f_{x}$ coefficient for each polluter but with different $q_{x}^{\max }$ coefficients in compliance with the information provided by the Adour-Garonne Agency on the organic matter produced by each polluter (see Figure 5). The ability of polluters to reduce their effluents at minimum costs thus depends only on their size. A "larger" polluter will be more efficient. The pollution produced is the maximal quantity of pollution that would be rejected when there is no abatement. The French Water Agency estimates this value for each polluter paying an effluent tax according to the activity sector and activity volumes.

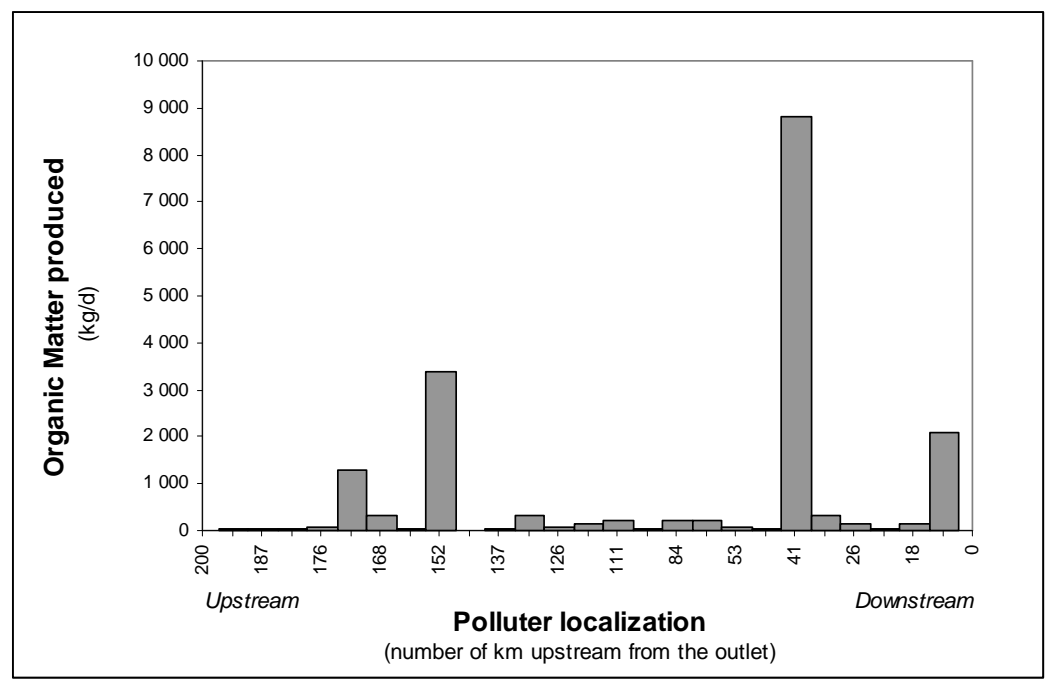

Figure 5. Organic Matter produced along the Isle River 
The diffusion of organic pollution in this river has been studied by the Institute of Geodynamics of the University of Bordeaux III in order to determine the transfer coefficients of each polluter. Selected transfer coefficients are identical for polluters located in the same town. The 25 municipalities represent the emission points (industries located in a municipality), and their immediate downstream areas are represented by the 25 receptors where the quality target must be achieved. Thus, in our practical case study, the abatement effort distribution minimizing the costs consists of 25 distinct abatement effort levels.

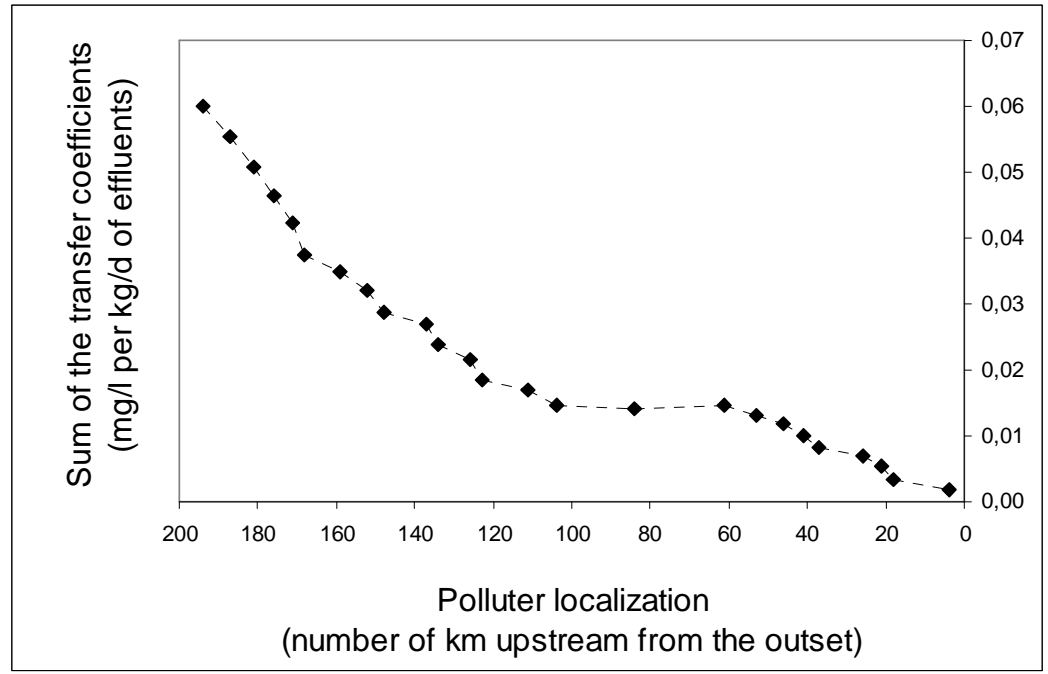

Figure 6. Transfer coefficients cumulated in each emission point

As shown in Figure 6, polluter's harmfulness decreases according to the upstream downstream direction as the river's flow rate increases and intensifies the dilution effect. The river flow had been modelled in order to take into account the dilution effect. However, a hypothesis of natural purification of $1 \%$ per kilometre had been assumed. Consequently, 25 transfer coefficients (one for each receptor) are associated to each of the 25 emission points. Theses coefficients are nulls for the receptors located upstream from the emission point.

\subsection{SIMULATION AND EMPIRICAL RESULTS}

According to the data provided by the Adour-Garonne Water Agency, we have estimated the total abatement $\operatorname{cost} \mathrm{C}_{\mathrm{N}}$ for each number of groups with the following optimization program: 


$$
\operatorname{Min} C_{N}=\sum_{x=1}^{70} C_{x}\left(q_{x}\right)=2\left[q_{x}^{\max }-q_{x}+q_{x} \cdot \ln \left(q_{x} / q_{x}^{\max }\right)\right]
$$

Under constraints

$$
\begin{array}{lc}
\bar{Q} \geq Q_{y}=\sum_{y=1}^{25} \sum_{x=1}^{70} \theta_{x y} \cdot q_{x} & \forall y \\
q_{x} \geq 0 & \forall x \\
c_{x}^{\prime}\left(q_{x}\right)=c_{x^{\prime}}^{\prime}\left(q_{x^{\prime}}\right) & \text { if } x \text { et } x
\end{array}
$$

The groups and the $c$ ' values for each group are interactively assessed.

We have used two tools: the Excel® Solver tool and an optimization tool using a simple genetic algorithm. As the formulated problem is not linear, the Excel@ Solver tool uses the non-linear "Generalized Reduced Gradient (GRG2)" optimization algorithm developed in the United-States by Leon Lasdon from the University of Texas (Austin) and Allan Waren from the University of Cleveland. A simple genetic algorithm (SGA) is used for determining the empirical efficiency gains, which are considered as decision variables related to the formulated problem. The algorithm used in this case was described by Goldberg (1994). Either tools can be more effective depending on the context. For instance, genetic algorithms provide on average better results for very demanding standards but provide poorer results for less demanding standards. The most relevant solutions, which have been obtained with both tools, have been selected.

Figure 5 shows that the Isle River comprises 4 main pollution sources, with far more pollutant production downstream. Upstream, polluters can be up to 34 times more harmful than downstream. In the situation where the "largest" polluters are the less harmful (Figure 2), the Maximum Efficiency Gains (MEG) are important for little demanding standards and decrease when the standard constraint becomes strong. This result is confirmed in Figure 7 with MEG reaching about $22 \%$ for little demanding quality objective (not quantity of pollution to remove from the environment as previous sections) and tending to 0 when the 
standard becomes strong (Figure 2, representing the quantity of pollution to be removed from the environment, the standard is more demanding on the right-side. While in the Figure 7, illustrating the standard to reach, the constraint is more important on the left-side).

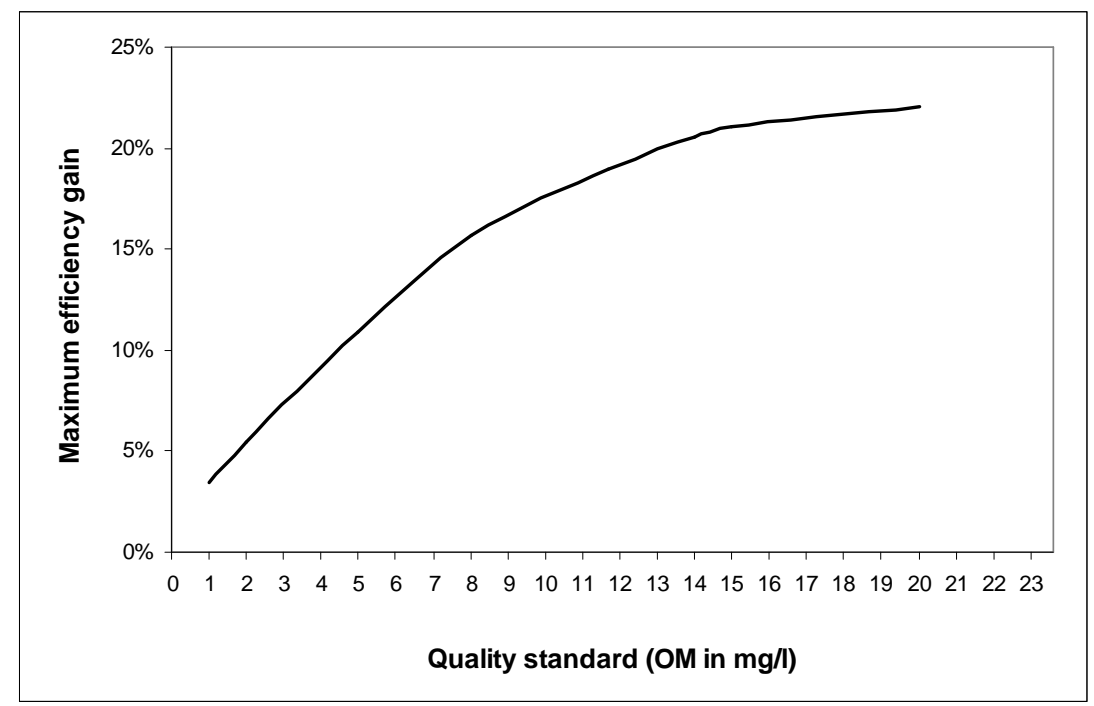

Figure 7. Maximum Efficiency Gains on the Isle River

Figure 8 illustrates the absolute abatement costs. As described in the section 5, the abatement discrimination effort is only interesting for "averagely" demanding standards. The actual benefit can only be assessed based on the absolute values of costs. For this river, the WFD standard equals to $14 \mathrm{mg} / 1$ of organic matters ${ }^{9}$, which corresponds to maximum efficiency gains of $20 \%{ }^{21}$. However, organic materials of non anthropogenic source or from Isle's tributaries are note considered in our simulation. The WFD standard is therefore more demanding in reality. 


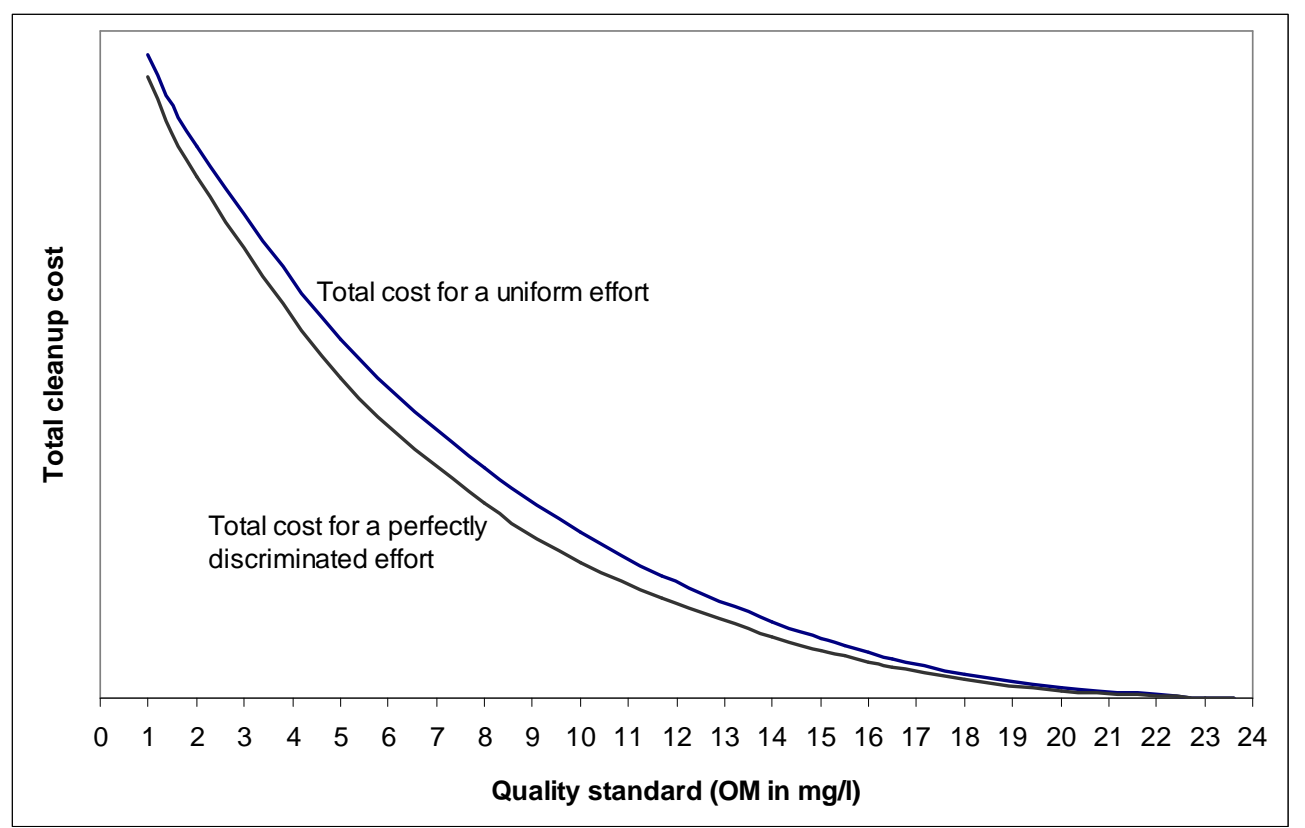

Figure 8. Costs according to the effort distribution

A "boundary" is set downstream of the largest pollution source at kilometre 41, according to a partial discrimination of polluters into two effort levels. As observed in Figure 9, the separation into two effort levels enables to "absorb" more than $50 \%$ of maximum efficiency gains and more than $70 \%$ of reasonably stringent standards. This "absorption" is about $77 \%$ for the standard, which is recommended today by the WFD ${ }^{21}$.

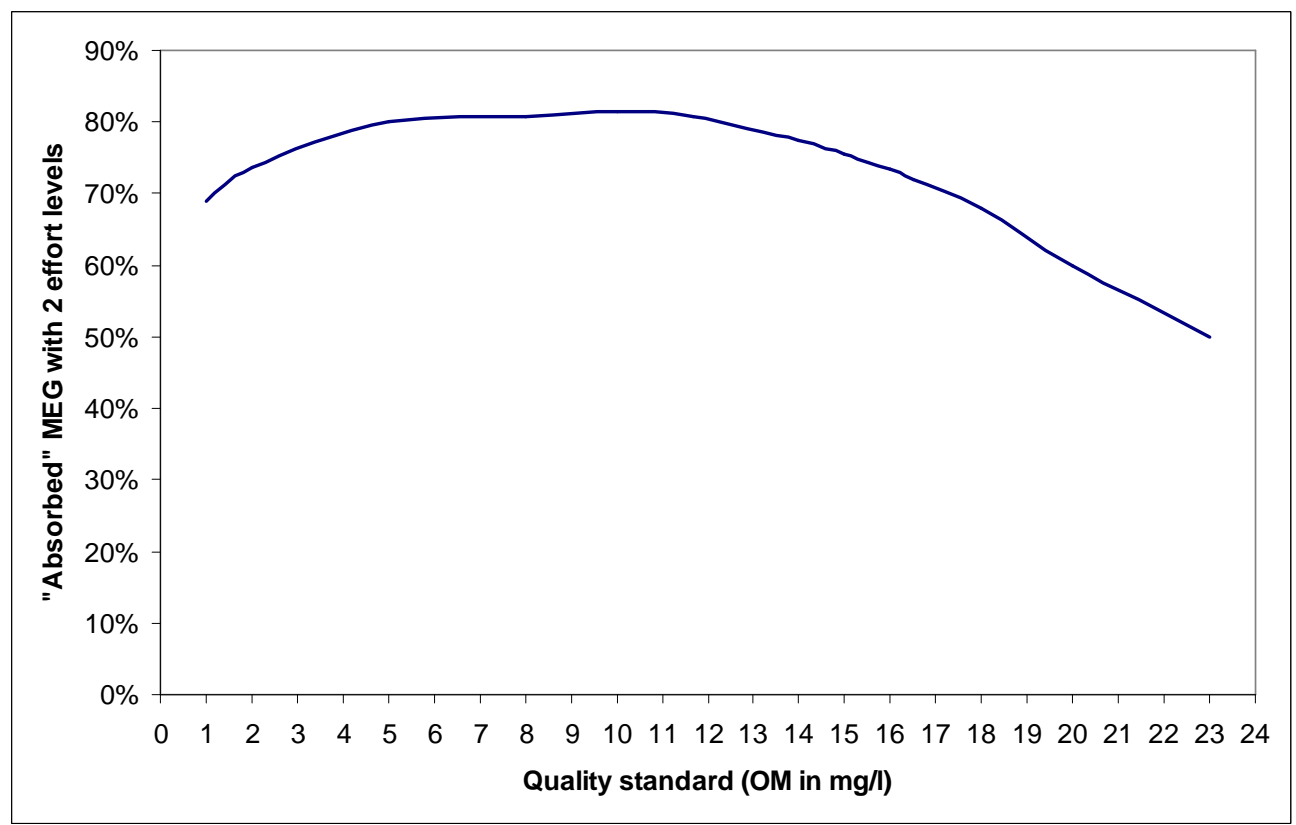

Figure 9. "Absorbed" MEG with 2 effort levels 
In the case of three levels of efforts, a second breakdown isolates the greatest pollution source. In order to achieve four effort levels, a third breakdown separates the two large pollution sources upstream at kilometres 171 and 152, and small polluters downstream.

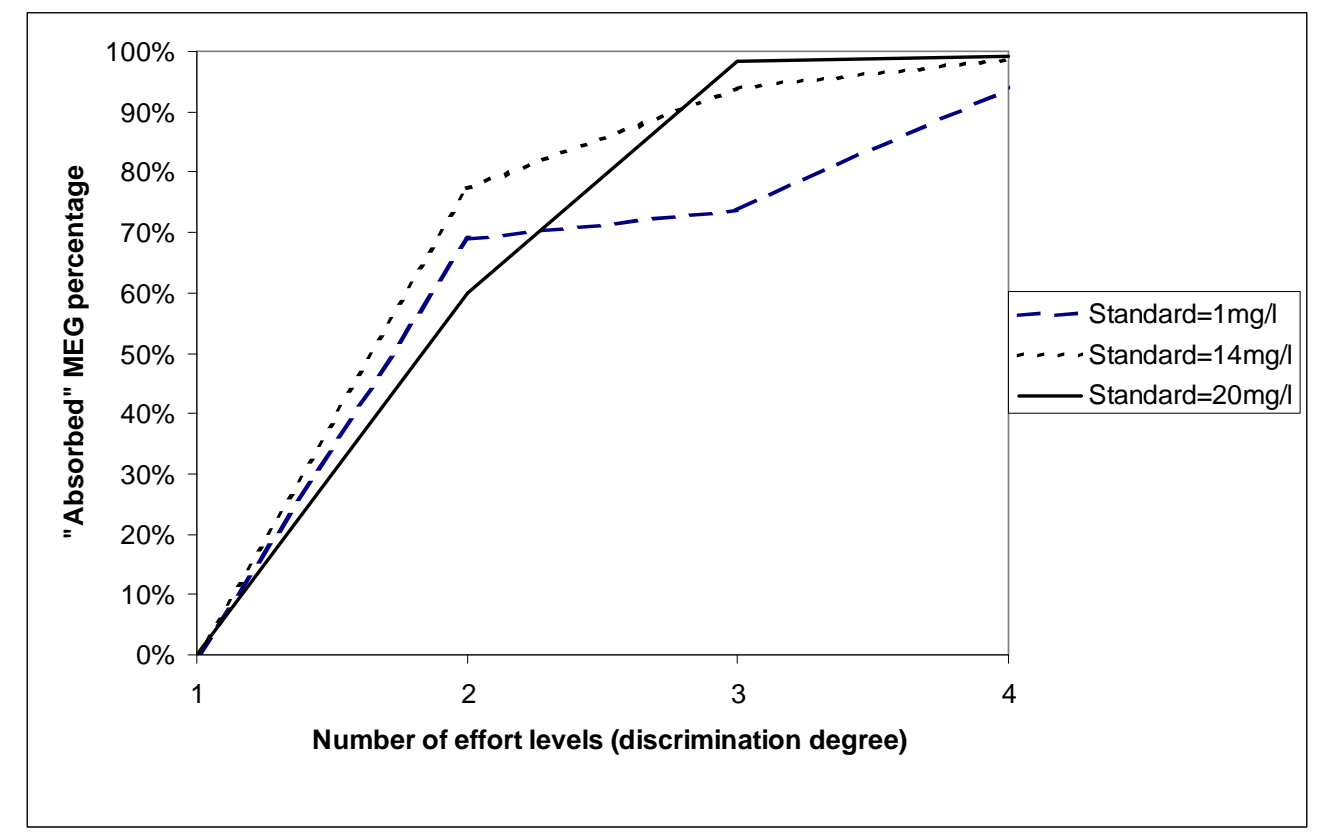

Figure 10. Percentage of "absorbed" GEM for each discrimination degree

Figure 10 confirms the theoretical results. If $\mathrm{AEG}_{1-\mathrm{N}}$ is slightly modified according to the standard, the MEG "absorption" is nearly integral with few effort levels. With the $14 \mathrm{mg} / \mathrm{l}$ WFD standard for organic matter, two levels of effort absorb $77 \%$ of MEG, $94 \%$ with three levels of effort and $99 \%$ with four levels of effort ${ }^{21}$.

\section{Conclusion}

The exemption procedure is a major issue for the Water Framework Directive implementation and outcomes. This procedure will assess the balance between economic and ecological interests that will be targeted. Member States and the European Commission therefore need solid elements to define cost and benefit assessment methods. Concerning costs, initial texts suggest that the programs of measures must be drawn up based on the abatement effort discrimination, but actual onsite application remains unclear. The uniform distribution of 
abatement effort enables to minimize constraints related to the discrimination. However, under certain conditions, it is more expensive. The purpose of this work was first to identify the conditions under which a uniform distribution of the effort leads to significant underefficiency, or when it seems interesting overall. Secondly, the aim was to determine which degree of discrimination should be recommended when a discrimination approach seems preferable. Several authors have dealt with the abatement effort discrimination issue: Atkinson and Lewis (1974), Destandau, (2000a), Destandau and Point (2000b), McGartland (1984), Montgomery (1972), Tietenberg (1974a, 1974b, 1995), etc. However, no specific research has dealt with the relationship between the different parameters of the optimization model and the relative benefit of discrimination. We argue that the European Commission must encourage Member States to discriminate the abatement effort when: ecological objectives are "averagely" demanding (neither very demanding nor very little demanding), transfer coefficients are very heterogeneous and polluters able to reduce the effluents at minimum costs are the least harmful. However, a limited number of effort levels is sufficient to make this policy effective. In this paper, based on the context of the WFD when designing the Programs of measures, the objective of the regulator is to reach an ecological target at minimum cost. A possible extension in the future could be to include an ecological benefit function to the regulator's objective function.

\section{Acknowledgements}

We would like to deeply thank the Adour-Garonne Water Agency and the Institute of Geodynamics of the University of Bordeaux III for giving us the information required to complete our empirical study. 


\section{Notes}

1. The effluents (or abated pollutions) are expressed in terms of continued flux generating equilibrium concentrations in the environment (or concentration removed from the environment). For constant effluents, the pollution concentration will obviously change with time for example according to climate conditions. So, the regulator must not only set the standards in terms of pollution concentration but also the dates, the frequency of measures and the minimum non-conformity rate required (see Destandau 2000a). If the transfer coefficients takes into account these specifications (for example by an estimation in the worst meteorological conditions to prevent the violation of the standard), the program of the planner can be considered as a static problem.

2. In France, water agencies geographically discriminate the pollution tax by allocating area coefficients according to the geographical localization to the basic rate of each pollutant (specific to each hydrographical basin). Furthermore, Klaassen, Forsund and Amann (1994) study the application of partial effort discrimination in relation to tradeable permits, as a specific exchange rate, which would define permit exchanges between different geographical areas.

3. With $q_{x}$ non equal to 0 for each $x$.

4. With a linear function, the quantity of abatement and then the abatement effort are limited. Thus, for very demanding target, the conditions [3] et [5] can to be not achieved for some polluters as soon as, respectively, $\sum_{y=1}^{Y} \lambda_{y} \theta_{x y}$ or $\frac{\sum_{y=1}^{Y} \lambda_{y} \sum_{x=1}^{X} \theta_{x y} q_{x}^{\prime}\left(\mathrm{E}_{U}\right)}{\sum_{x=1}^{X} q_{x}^{\prime}\left(\mathrm{E}_{U}\right)}$ will be higher than the maximum effort. So, we suppose here that all the polluters are large enough $\left(q_{x}^{\max }\right.$ high) in order to respect theses relations. The impact of the parameter $q_{x}^{\max }$ on the relative efficiency gains is not tackled with a linear function.

5. With a linear effort function, we obtain: $q_{x}^{\prime}\left(E_{x}\right)=e f f_{x}$

6. This result has to be in perspective when the effort functions are limited, because an increasing standard constraint will enhance the number of polluters which will have to abate their whole produced pollution (in this case we have not the relations [3] and [5] for all the polluters).

7. With a Barrett-type effort function: $q_{x}^{\prime}\left(E_{x}\right)=e f f_{x} \cdot q_{x}^{\max } \cdot \exp ^{\left(-e f f_{x} \cdot \mathrm{E}_{x}\right)}$

8. We don't demonstrate it here, but the affectation problem is modifying according to the convexity of the functions. When the standard tends towards 0, thus cancelling any constraint, polluter "groups" are equally 
important which is similar to the result obtained with linear functions. However, more demanding standards will generate increasingly unequal "groups", with the most harmful polluters belonging to the largest "group".

9. The WFD does not define a standard for organic matter but differentiates COD and five-day BOD, as opposed to the tax bases of water agencies (and therefore to the data available on produced and discharged quantities) which, up to now, were calculated by taking $2 / 3$ of five-day BOD and $1 / 3$ of COD. We have therefore converted WFD standards using these ratios so as to obtain an organic matter standard which could be compared to polluters' characteristics. However, in the future, for consistency, water agencies will differentiate five-day BOD and COD.

\section{References}

Atkinson, S.E., Lewis, D.H. (1974), 'A Cost-Effectiveness Analysis of Alternative Air Quality Control Strategies', Journal of Environmental Economics and Management 1:237-250.

Barrett, S. (1994), 'Self-enforcing International Environmental Agreements', Oxford Economic Papers 46:878-894.

Baumol, W.J. (1972), 'On Taxation and the Control of Externalities', The American Economic Review 62(3):307-322.

Baumol, W.J. (1974), ‘On Taxation and the Control of Externalities: Reply', The American Economic Review 64(3):472.

Baumol, W.J., Oates, W.E. (1988), The Theory of Environmental Policy, $2^{\text {nd }}$ edition, Cambridge University Press, Cambridge.

Bosch, D.J., Ogg, C., Osei, E., Stoecker, L. (2006), 'Economic Models for TMDL Assessment and Implementation', American Society of Agricultural and Biological Engineers 49(4) :1051-1065.

Cropper, M.L., Oates, W.E. (1992), 'Environmental Economics: A Survey', Journal of Economic Literature 30(2):675-740. 
Destandau, F. (2000a), Régulation de la pollution de l'eau par une redevance spatialisée, thèse de doctorat en Sciences Economiques, Université Bordeaux IV.

Destandau, F., Point, P. (2000b), 'Cheminement d'impact et tarification efficace sur un bassin versant', Revue Economique 51(3) :609-620.

Destandau, F., Point, P. (2003), 'Analyse coût efficacité et discrimination partielle de la redevance', dans Eau et Littoral : Préservation et valorisation de l'eau dans les espaces insulaires, Ferrari S., Point P., Les Editions Karthala, Paris :301-330.

Duggan, J., Roberts, J. (2002), 'Implementing the efficient Allocation of Pollution', American Economic Review 92(4) :1070-1078.

Kaika, M., Page, B. (2003), 'The EU water framework directive ; part 1. European policymaking and the changing topography of lobbying', European Environment 13(6):314-327.

Klaassen, G., Forsund, F., Amann, M. (1994), 'Emission Trading in Europe with an Exchange Rate', Environmental and Resource Economics 4:305-330.

McGartland, A.M. (1984), Marketable Permit System for Air Pollution Control: an Empirical Study, Ph.D. dissertation, University of Maryland.

Montgomery, W.D. (1972), 'Markets in Licences and Efficient Pollution Control Programs', Journal of Economic Theory 5(3):395-418.

Thomas, A. (1995), 'Regulating Pollution under Asymmetric Information: The Case of Industrial Wastewater Treatment', Journal of Environmental Economics and Management 28:357-373.

Tietenberg, T.H. (1974a), 'Derived Decision Rules for Pollution Control in a General Equilibrium Space Economy', Journal of Environmental Economics and Management 1:3-16.

Tietenberg, T.H. (1974b), 'On Taxation and the control of Externalities: Comment', The American Economic Review 64(3):462-466. 
Tietenberg, T.H. (1995), 'Tradeable Permits for Pollution Control when Emission Location Matters: What have We learned?', Environmental and Resource Economics 5:95-113.

Tietenberg, T.H. (2006), Emissions Trading: Principles and Practice, $2^{\text {nd }}$ edition, Resources for the Future, Washington DC, USA.

Weitzmann, M.L. (1974), 'Prices vs. Quantities', Review of Economics Studies 41:477-491. 